\title{
A Novel Design Competition for Third-Year Civil Engineering Students
}

\author{
Dr. Janaka Y. Ruwanpura \\ Assistant Professor (Project Management) and Associate Chair in Design Engineering \\ Department of Civil Engineering \\ Faculty of Engineering \\ University of Calgary \\ janaka@ucalgary.ca
}

\begin{abstract}
At many Canadian universities, there are few courses for design education in the civil engineering curriculum except in fourth year. This paper explains an innovative approach introduced by the author to promote design education using a design competition at the University of Calgary. Through this design competition, third-year students learn design concepts and apply them using a real project, integrate several civil engineering deliverables in one project without doing them in a separate course, and gain experience that prepares them for their final-year design course. The eight courses included in the competition comprise all civil engineering aspects, including structural, geotechnical, transportation, environmental, construction, material, and project management. This inaugural year's design competition is based on the new Alberta Children's Hospital Project. The paper discusses the competition's purpose, structure, student participation, deliverables, and successful outcome.
\end{abstract}

\section{Introduction}

The design engineering process is clearly critical to the economic well-being of both developed and developing countries. Teaching engineering without design is not engineering education [1]. However, in many engineering curriculums, teaching design is limited to the students' final year. The Faculty of Engineering at the University of Calgary has recognized Design Engineering as a vehicle for integrating all the engineering and non-engineering knowledge and disciplines to create a new generation of engineers with strong innovation capacities and capabilities. The Faculty of Engineering is, therefore, committed to building a stronger Design Engineering (DE) program. The NSERC Chair in Life Cycle Environmental Design Engineering has implemented various new initiatives to improve the DE program in the Faculty of Engineering at the University of Calgary. One such idea was to incorporate DE through the first to the final years' curriculums. The newly created first-year, full-year design course, Engineering Design and Communications $I$ and $I I$, was introduced in September 2002. All first-year engineering students are required to take this full-year compulsory course. The course uses design projects to facilitate the study of various design and communication topics, and to convey design ideas [2].

Because it is difficult to bring additional courses to the engineering curriculum for second- and third-year engineering programs, it was necessary to develop innovative ideas to bring DE into the second and third years. This paper explains one of the innovative ideas planned and implemented in the 2004/5 academic year for third-year Civil Engineering 
undergraduates to improve their knowledge of DE. The idea was a design competition for the third-year students that integrate multidisciplinary civil engineering concepts. The Department of Civil Engineering at the University of Calgary has several expert areas: Structural, Geotechnical, Transportation, Materials, Water Resources, Environmental Engineering, and Project Management. One of the main objectives of the design courses and activities was to integrate the engineering areas mentioned above with related project management issues while providing real-life problems for their design activities.

The purpose of this "Design" education module and competition was, therefore, to improve and enhance the students' design education and practice of all civil engineering and related project management aspects. The benefits were as follows:

- The students learned design concepts and applied them in their third year using a real project.

- The students were able to integrate several civil engineering deliverables in one project without doing them in separate courses.

- The students gained experience that prepared them for their final-year design course.

\section{STRUCTURE OF THE COMPETITION}

A third-year student typically registers for the following eight courses during the Fall and Winter semesters:

Fall

- ENCI 413: Introduction to Civil Engineering Materials

- $\quad$ ENCI 461: Mechanics of Materials

- ENCI 471: Introduction to Project Management

- ENCI 481: Introduction to Environmental Engineering

Winter

- ENCI 423: Soil Mechanics

- ENCI 451: Basic Structural Design

- ENCI 465: Engineering and Construction Management

- ENCI 473: Introduction to Transportation Planning

With each of these courses, there is an assignment or part of an assignment that uses design and/or project management principles related to a real project. The following are the details of the competition:

1. The competition comprises the deliverables of 8 class assignments (mandatory for all students in third year), an executive summary report, and a poster. Assignments are selected from each of the disciplines taught in the third-year curriculum under the abovementioned courses. Students were given the basic drawings and information related to the project. Grading for each assignment was part of the individual course.

2. The individual instructors created the assignments' details; for example, in ENCI 413 , the students were asked to suggest the use and suitability of particular materials in the design of the project. The students produced an executive summary and a poster at the end of the semester.

3. The design competition used the results of the assignments, in total, and the marks for the poster and executive summary to determine the winners. The details related to each of the assignments, executive summary, and the posters were given to the students at the appropriate times. The grades were broken down as follows:

- Assignments: $80 \%$ (each assignment is $10 \%)$

- Executive Summary: $10 \%$

- Poster: $10 \%$

4. The students were given clear instructions about the deliverables at various points during the semesters. For example, the executive summary had to include only key information relevant to the design and project management work and the lessons learned. The students were asked to include the following in the executive summary: a clear introduction to the design and project management work in each of the assignments, an outline of the key contributions, and suggestions of how someone could integrate the assignment's deliverables to the overall theme. They had to include all key design decisions and justifications for each design assignment, discuss the lessons learned and how these affected their learning experiences, and a critique of the type of assignments used for the competition by each course. 
5. A poster session was held during the Winter semester on the day that the Faculty of Engineering had its annual Design Open House. The poster included the objectives/ purpose, technical content, deliverables, and related graphics.

6. A panel of judges (comprising academia and industry) decided the winners by reviewing the executive summaries, the posters, and the assignment binders, and also by interviewing the students during the open house.

\section{IMPLEMENTATION}

During the 2004/5 academic year, when this idea was implemented, it was optional to third years. This year's design competition was related to the New Alberta Children's Hospital that is being built west of the University of Calgary main campus. Fifteen student teams participated for the competition in Fall 2004, but only five of the fifteen teams remained in the final competition. The main reasons for dropping out of the student teams were the course's heavy workload at the end of the academic year, and low marks obtained on the assignments. The students were asked to submit an application and a fee of $\$ 10$ by Oct $8^{\text {th }}, 2004$ to register for the competition. A maximum of three students were allowed per team.

The individual instructors of the courses prepared the assignments related to the competition. There were several pieces of information required that were provided by Calgary Health Region, Stentec Consulting and Ellis-Don Constructor Company during the academic year. The purpose of each assignment follows:

1. To design an Ambulance Shed that will withstand snow and wind loads, and maintain general structural stability (ENCI 451).

2. To calculate the total state of stress for an Lshaped beam subjected to forces (ENCI 461).

3. To study different building materials using Electron Microscopy and matching material behavior with proper construction use (ENCI 413).

4. To determine Pump Capacity for Foundation Excavation to maintain suitable groundwater levels (ENCI 423). See Figure 1.
5. To produce a Project Charter with a Work Breakdown Structure for a proposed building in the hospital project (ENCI 471).

6. To determine the most suitable contract type for the construction of the same building mentioned above (ENCI 465).

7. To determine the impact on the existing transportation system from the construction of the new Alberta Children's Hospital and to determine the cost viability in constructing a new interchange on Shaganappi Trail (ENCI 473).

8. To produce a Erosion and Sediment Control Plan for the construction site (ENCI 481).

Fig. 2 shows the poster prepared by one student group, and Fig. 3 shows a picture of the annual Design Open House of the Faculty of Engineering at the University of Calgary.

Winners were awarded prize money: $\$ 1000$, $\$ 500, \$ 300$ for $1^{\text {st }}, 2^{\text {nd }}$ and $3^{\text {rd }}$ places, respectively. The winners of each best assignment were awarded $\$ 100$ each.

\section{COMMENTS FROM STUDENTS}

The success of a new design education concept depends on many aspects. The feedback from students who participated in the competition is very important for making improvements for future years. Following are sample comments received from the students regarding the success of the competition:

"In the Mêlée that has been 3rd year engineering, we did not recognize the continuity of our curriculum until we compiled the fruits of our labours for this competition. Writing about each assignment really brought home the functionality behind the theory. Participating in this competition has provided us with a deeper understanding of the concepts of civil engineering."

"The 3rd year design competition gave us a different perspective from those who chose not to participate. Each course conveyed the aspects of a construction project and how management integrates the different disciplines together to create a deliverable finished product."

"From the experience, we are now able to apply theories learned in the classroom to an actual project demonstrating the relevance of course 
material. We would encourage more students to participate to broaden their view of the interconnected civil engineering fields." apply to real-life projects. It was very beneficial to see how the different disciplines of civil engineering are involved in one project."

"Throughout the process of this competition, we learned about design concepts and how they

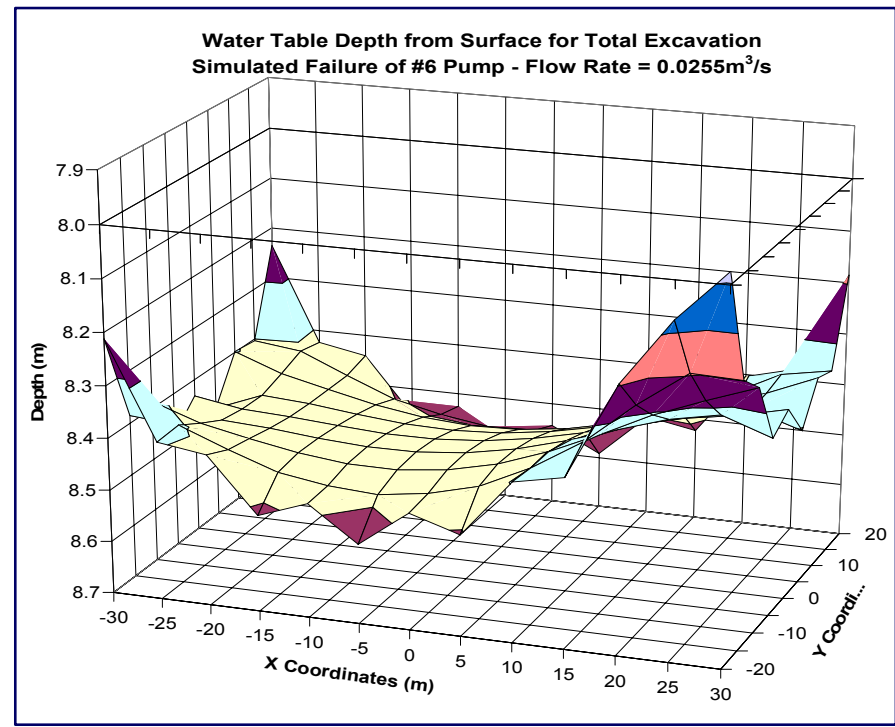

Figure 1: Part of the assignment deliverable for ENCI 423 course

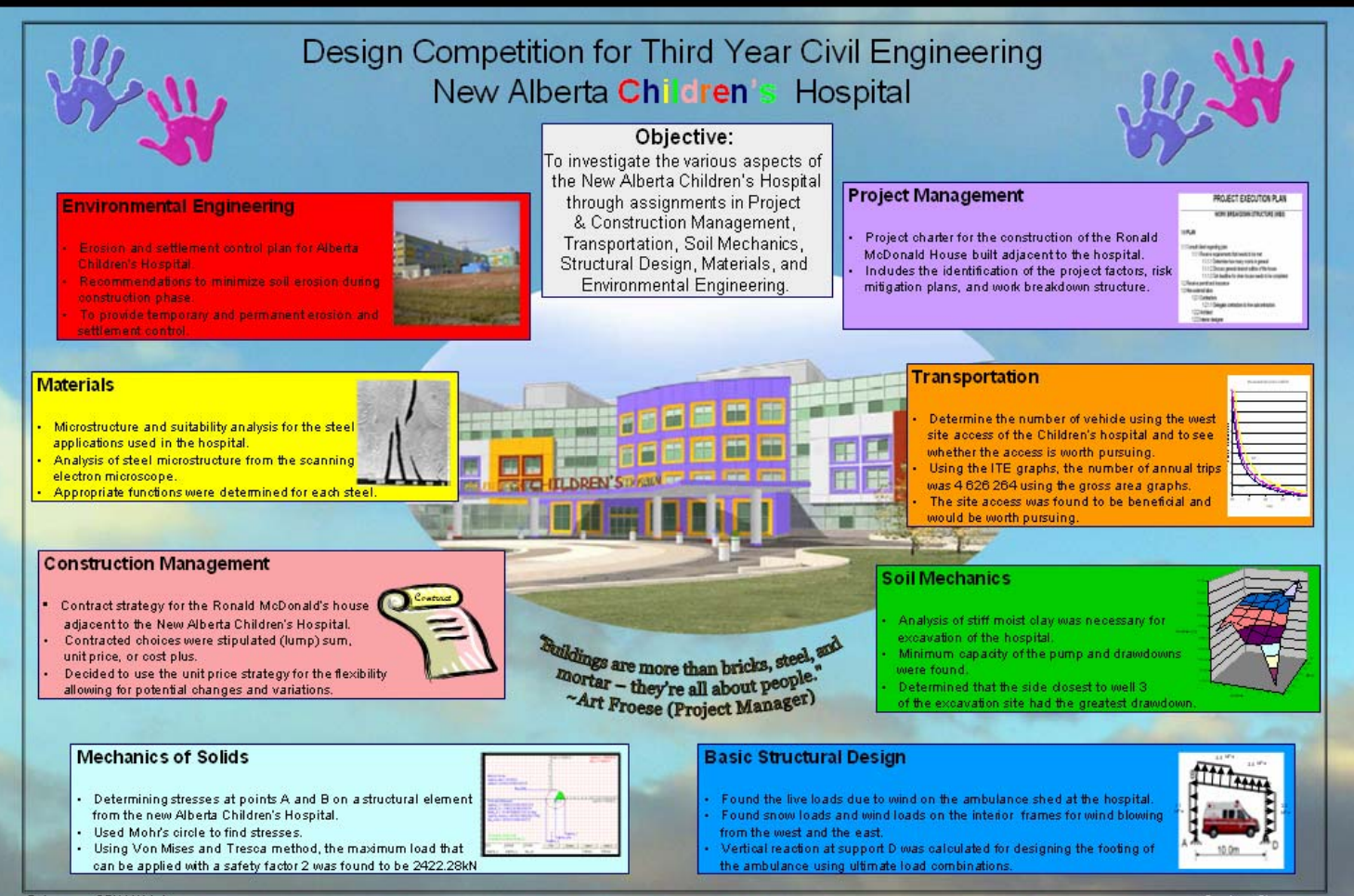

Figure 1: Poster designed by one student group 


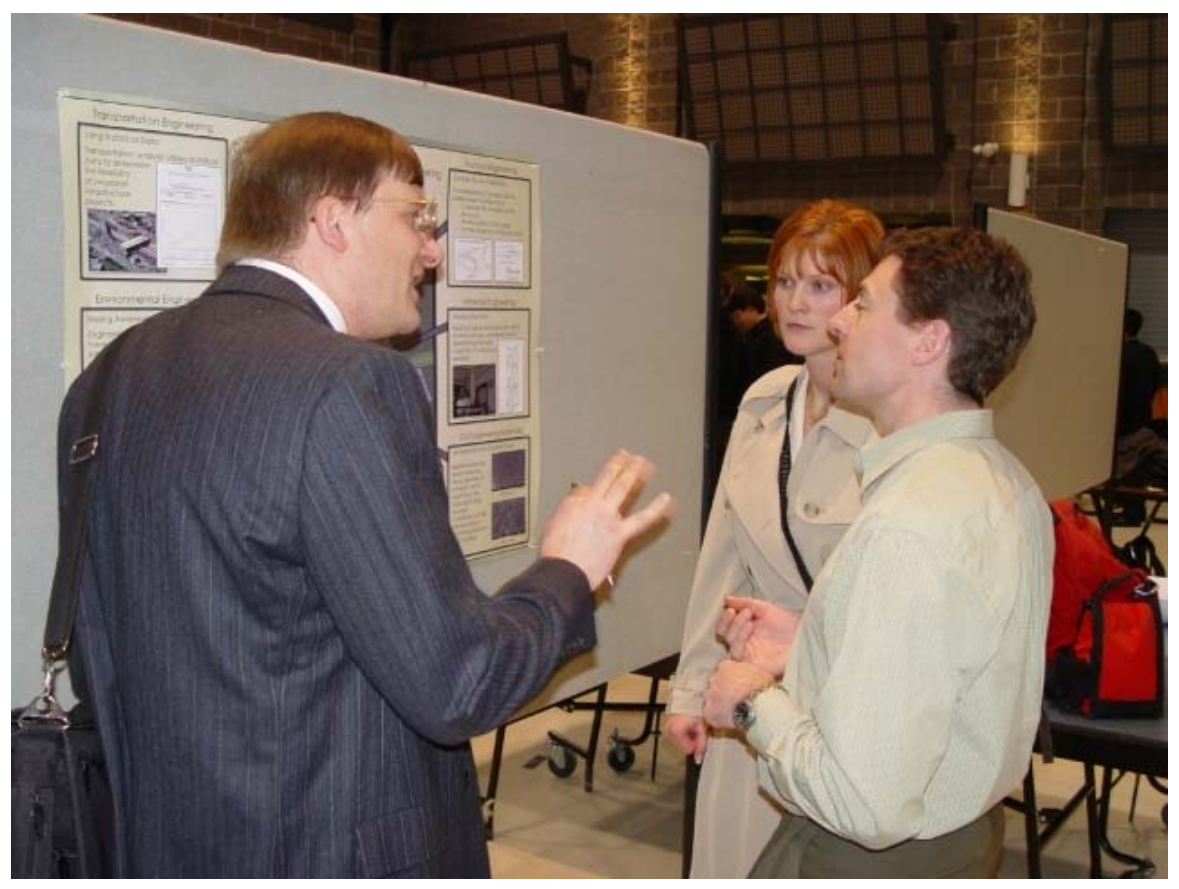

Figure 2: A judge interviewing a student team during the Design Open House

"We learned about the importance of team work and communication when dealing with a multidisciplinary design. This newly gained experience will help us in preparation for our final year design course."

"Our group is proud of the results we have achieved, and we believe that the design competition has improved and enhanced our design education of civil engineering and project management aspects related to real life projects."

"The competition was beneficial since we were able to apply our knowledge from different classes to a large-scale construction project. Through the Interactive learning, we were able to see how numerous tasks are involved in developing this large structure and how excellent project management skills are needed to compile a project of such a magnitude."

"The exposure to a single unified theme throughout each of the civil engineering subdisciplines was a unique experience that not only promoted the practical application of engineering theory, but also helped students to select a path of specialization."
"Civil engineering has the most liberal range of sub-disciplines, and the design competition offered an innovative challenge that tied together many of the classes."

The students, however, did suggest a few improvements to the competition for future years. Following are the major suggestions:

1. Allow the students to see all the assignments at the beginning of the semester so that they could plan ahead for the deliverables.

2. Create assignments very specific to the real project rather than generic to any project. The students felt that some of the assignments did not fit very well with the real project.

3. Schedule the assignments of the courses more towards the first two months of each semester rather than towards the end of the semesters.

4. Develop assignments with better integration among the same technical areas (such as structural courses).

\section{CONCLUSION}


This is the very first time in the history of engineering education in Canada that Design Experience was integrated into a third-year curriculum though a design competition by means of an initiative and concept of the author. The design competition conducted in 2004/5 as a pilot project was very successful and had very positive comments from students. It is planned to continue with the competition in future years. Modifications will be made based on the lessons learned during the inaugural year. The Faculty of Engineering of the University of Calgary through the leadership of the NSERC Life Cycle Chair is planning to implement similar types of competitions for other departments of the faculty in the near future.

\section{ACKNOWLEDGEMENTS}

The author wishers to thank Dr. Peihua Gu, NSERC Life Cycle Environmental Design Engineering Chair at the University of Calgary for the opportunity given to improve design education in engineering. The author extends his sincere thanks to Dr. Mohamed Nazir, Research Associate at the Department of Civil Engineering for his support in assisting to organize the competition. The acknowledgments are also extended to the students who participated in the competition, the judges for their contributions, and the Calgary Health Region, Stentec Consulting, and Ellis-Don Construction for providing information to the students about their deliverables. Finally, the author thanks the NSERC Life Cycle Environmental Design Engineering Chair and the Department of Civil Engineering at the University of Calgary for sponsoring the competition.

\section{REFERENCES AND BIBLIOGRAPHY}

[1] Wankat, P. C., and Oreovicz, F. S. (2001)

"Teaching engineering."

https://engineering.purdue.edu/ChE/News and Events/Publications/

teaching_engineering/index.html (August 2002). [2] Gu, P. (2005). Forty-Eight Month Progress Report-NSERC Life Cycle Environmental Design Engineering Chair, Internal Report submitted to NSERC. 